\title{
On interpreting studies of tracer transport by deep cumulus convection and its effects on atmospheric chemistry
}

\author{
M. G. Lawrence ${ }^{1}$ and M. Salzmann ${ }^{1,2}$ \\ ${ }^{1}$ Max-Planck-Institut für Chemie, Mainz, Germany \\ ${ }^{2}$ Atmospheric and Oceanic Sciences Program, Princeton University, Princeton, New Jersey, USA
}

Received: 7 May 2008 - Published in Atmos. Chem. Phys. Discuss.: 19 June 2008

Revised: 29 August 2008 - Accepted: 8 September 2008 - Published: 21 October 2008

\begin{abstract}
Global chemistry-transport models (CTMs) and chemistry-GCMs (CGCMs) generally simulate vertical tracer transport by deep convection separately from the advective transport by the mean winds, even though a component of the mean transport, for instance in the Hadley and Walker cells, occurs in deep convective updrafts. This split treatment of vertical transport has various implications for CTM simulations. In particular, it has led to a misinterpretation of several sensitivity simulations in previous studies in which the parameterized convective transport of one or more tracers is neglected. We describe this issue in terms of simulated fluxes and fractions of these fluxes representing various physical and non-physical processes. We then show that there is a significant overlap between the convective and large-scale mean advective vertical air mass fluxes in the CTM MATCH, and discuss the implications which this has for interpreting previous and future sensitivity simulations, as well as briefly noting other related implications such as numerical diffusion.
\end{abstract}

\section{Introduction}

Deep cumulus convection ("DCC") has several important influences on atmospheric chemistry, such as: vertical transport of water and trace substances; scavenging of soluble gases and aerosols by precipitation; formation of cirrus anvils which influence radiative transfer and thus photolysis rates, and which provide surfaces for heterogeneous chemical reactions; and generation of lightning, which produces nitric oxide. DCC also affects atmospheric chemistry indirectly through latent heating and its contributions to the solar and infrared radiation budgets, and in turn through its role in both

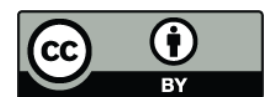

Correspondence to: $\mathrm{M}$. G. Lawrence (lawrence@mpch-mainz.mpg.de) synoptic and global scale circulations. Here we focus specifically on the direct effects of deep convection via vertical transport. DCC is an integral part of the overturning of air masses in the troposphere, with rapid updrafts transporting air masses and tracers from the boundary layer to the upper troposphere, and downdrafts in reverse from the free troposphere into the boundary layer. This has profound effects on the budgets of trace gases and aerosols throughout the troposphere, particularly on those with lifetimes in the range of about a day to a couple weeks.

Many previous studies have examined various aspects of the effects of DCC on atmospheric chemistry. One particular question which several of these studies have addressed is: "What is the effect specifically of transport due to DCC, including rapid updrafts and downdrafts, as well as associated large-scale subsidence, on ozone-related atmospheric chemistry?" One of the earliest studies addressing this from an observations perspective was Dickerson et al. (1987), who found that the mixing ratios of $\mathrm{O}_{3}$ and the $\mathrm{O}_{3}$-precursor $\mathrm{CO}$ were substantially enhanced in the outflow of a deep cumulus cloud that they sampled, compared to the surrounding "background" troposphere.

These observations of DCC transport have been followed by other similar observations, and have also been augmented by modeling studies, using both cloud-resolving models as well as global models. The earliest cloud resolving model simulations (e.g., Pickering et al., 1990, 1992, 1993) showed that the upward transport of $\mathrm{O}_{3}$ and especially its precursors can result in substantial local increases in tropospheric $\mathrm{O}_{3}$ in the outflow of deep convection, as well as increasing the tropospheric $\mathrm{O}_{3}$ column over polluted regions, since the lifetimes of these gases and the $\mathrm{O}_{3}$ production efficiency (e.g. per $\mathrm{NO}_{\mathrm{x}}$ molecule) both tend to increase with altitude.

On the other hand, Lelieveld and Crutzen (1994) pointed out that downward mixing of $\mathrm{O}_{3}$-rich air from the upper troposphere (UT) towards the surface can reduce the column mean lifetime of $\mathrm{O}_{3}$. They used a simple tropospheric

Published by Copernicus Publications on behalf of the European Geosciences Union. 
chemistry-transport model (CTM), MOGUNTIA, to compute the overall effects of convective transport of ozone and its precursors. This was done by switching off the transport of ozone and its precursors by the convection parameterization, but keeping everything else in the model the same, including the meteorology. Doing so, they found that the reduction in ozone above clean regions outweighed the effects of mixing above polluted regions, resulting in a net $20 \%$ decrease in tropospheric $\mathrm{O}_{3}$ in the simulation including parameterized DCC transport of the gases versus the simulation neglecting DCC transport.

Thus far, the study of Lelieveld and Crutzen (1994) has been directly followed up with two others using global models to examine the net effects of DCC on ozone, but with conflicting results. In Lawrence et al. (2003b), we used a more complex CTM, MATCH-MPIC, and separated the effects into two components: the transport of ozone itself, and the transport of the precursors. Using the same approach as in Lelieveld and Crutzen (1994), we found a significant reduction of ozone due to its vertical overturning via DCC over clean regions, supporting the basic hypothesis of Lelieveld and Crutzen (1994) that this effect can be of global importance. However, in contrast to Lelieveld and Crutzen (1994), we found that the effect due to the vertical transport of ozone precursors by DCC outweighed the effect of the transport of $\mathrm{O}_{3}$ itself, leading to a net $12 \%$ increase in tropospheric $\mathrm{O}_{3}$ when we included parameterized DCC transport of all trace gases (including $\mathrm{O}_{3}$ ) versus when we neglected it. In further simulations, we could determine that $\mathrm{NO}_{\mathrm{x}}\left(=\mathrm{NO}+\mathrm{NO}_{2}\right)$ was the main precursor responsible for this. Continued interest in this topic has been aroused by Doherty et al. (2005), who repeated our simulations with a comparably complex, Lagrangian chemistry-GCM (STOCHEMHadAM3), and again found differing results. In their simulations, the convective overturning results in a $13 \%$ decrease in the global ozone burden, and the primary effect from the precursors is due to hydrocarbons like isoprene, in contrast to our results in Lawrence et al. (2003b). Simulations of this nature are now being considered for use within a multi-model comparison and process analysis in the IGAC/SPARC Atmospheric Chemistry and Climate (AC\&C) initiative.

A few other studies have also employed this methodology of switching off the parameterized DCC transport of particular components for examining related issues. For instance, Collins et al. (1999) have examined the role of convection in determining the budget of odd hydrogen in the upper troposphere, and in Lawrence et al. (1999) we examined the effects of convective transport of ozone specifically on the production of extreme minima in $\mathrm{UT}_{3}$ over the equatorial Pacific. Mahowald et al. (1997b) showed that in simulations which included a parameterization for DCC transport, UT mixing ratios of radon were about $50 \%$ greater than in a simulation which excluded the parameterized transport. The novel aspect of the influence of DCC on interhemispheric transport was considered by Lintner (2003), who used artificial tracer simulations with and without the transport by parameterized deep convection to show that the mixing away from the surface due to convection results in a reduction of the rate of interhemispheric transport of tracers with a surface source. Finally, in a related study, Erukhimova and Bowman (2006) have examined general global transport characteristics using 3-D trajectories including and neglecting the effects of the parameterized DCC transport in the NCAR/CCM3.

Most of these global simulations have been interpreted as being representative of the net effects of DCC transport. For example, in our previous work (Lawrence et al., 2003b), we indicated that "the net effect of convective transport of all trace gases $\left(\mathrm{O}_{3}\right.$ and precursors together) is a $12 \%$ increase in the tropospheric $\mathrm{O}_{3}$ burden," and we described the setup of the test runs as follows: "In the test runs we completely shut off the convective transport of $\mathrm{O}_{3}$ or of all trace gases so that comparing the results to the respective BASE run [with convective transport active for all gases] indicates the net effect of each process." Lelieveld and Crutzen (1994) stated similarly: "Simulations with a three-dimensional global model suggest that the net result of these counteractive processes is a 20 percent overall reduction in total tropospheric $\mathrm{O}_{3}$," and "The role of deep cloud convection in the tropospheric $\mathrm{O}_{3}$ budget is clearly demonstrated if we omit the [parameterized] convective vertical exchange of trace gases from our model." Doherty et al. (2005) also state this in various ways, such as "convective mixing in our study reduces the $\mathrm{O}_{3}$ burden", and Collins et al. (1999) state that "the effect of convection is to increase upper tropospheric $(300-200 \mathrm{hPa}) \mathrm{HO}_{\mathrm{x}}$ globally by over $50 \%$ ".

Recently, however, we have come to realize that this is not a correct interpretation of these simulation results. The reason for this misinterpretation is discussed in detail in the following sections. Historically, this has largely arisen due to the traditional split-operator design of advection and convection processes in CTMs and GCMs. A more correct interpretation of the simulations noted above is that they mainly show two effects: first, a specific component of the overall DCC mass fluxes is added when the convection parameterization is included, and second, the parameterization allows the overall DCC transport to be represented as rapid, episodic vertical transport events, versus a more continuous mean transport. It is worth noting that some studies have indeed formulated their interpretation more along these lines; for instance, Mahowald et al. (1997b) state that "in the upper troposphere concentrations of ${ }^{222} \mathrm{Rn}$ can change by $50 \%$ depending on whether a moist convection scheme is used". However, in subsequent discussions even of that study, as well as of the others mentioned above, the simulations are nevertheless often misinterpreted as quantifying the overall role of the DCC transport, not just components of the DCC transport which are added or modified due to including the parameterization. We hope this paper will raise awareness among the atmospheric chemistry community of this feature of CTMs and the resulting implications for trace gas and 
aerosol simulations, and will prevent misinterpretations of similar future simulations, for instance those planned in the framework of model intercomparisons. In the following sections we describe the problem in terms of simulated mass fluxes, and consider the magnitude of the problem based on 3-D model fields. We then discuss the implications for atmospheric chemistry sensitivity studies and alternate approaches to examining the effects of deep convection, such as that developed by Hess (2005). We also briefly describe two additional related implications, numerical diffusion in Eulerian models, and the interpretation of Lagrangian trajectory studies, before concluding with a summary and outlook for future research on this topic.

\section{Explanation: treatment of deep cumulus convective and large-scale mean mass fluxes}

In all contemporary general circulation models (GCMs), numerical weather prediction (NWP) models and chemistrytransport models (CTMs) that we are aware of, the transport of tracers by deep cumulus convection and by advection are treated as split operators (one exception to this, which is currently under development and testing, is noted below in the conclusions). Each of these processes operates individually on the 3-D tracer fields during the model time step, though in some modeling frameworks the tendencies are summed and only integrated all together at the end of the time step. In either case, there is no explicit connection between the mass fluxes in the deep convection parameterization and the mass fluxes in large scale circulations such as the Hadley and Walker cells. There is, however, an implicit connection due to modification of the water vapor and temperature profiles.

Traditionally, it is assumed that DCC transport and largescale advection are individually mass conserving. For advection, this implies that any convergence into a grid cell (along one or two axes) must be exactly balanced by divergence from the grid cell (along the other one or two axes). The 3-D resolved mean wind fields used for advection will therefore contain a vertical component which is based on the convergence and divergence in the horizontal wind fields. This vertical mass flux can be physically interpreted as the mean regional upwelling or downwelling, due to a combination of various processes such as deep convection and upwelling through shallower clouds and cloud-free air, averaged over the scale which is resolved by the model. For the DCC parameterization, guaranteeing individual mass conservation has the implication that the transport of airmass is treated as a closed process in a single model column: any upward mass transport in convective updrafts is exactly balanced by the downward transport in convective downdrafts plus the between-cloud mass-balance subsidence in that column.

Mass conservation is an important requisite for any CTM or GCM. However, the individual mass conservation in the advection and DCC components of these models results in an inconsistency in some regions, for instance the low-level, large-scale convergence region of the upward branch of the Hadley cell. As early as Riehl and Malkus (1958) it was realized that the mean upward mass flux in the Hadley cell cannot be entirely accounted for by slow, mean upward transport, with mixing of air masses in the middle troposphere as they ascend, since this would not be able to produce the observed moist static energy profile with a minimum in the middle troposphere. Instead, at least a substantial fraction, and probably most of the mean upward transport has to occur in deep convective updrafts (so-called "hot towers"), which rapidly transport airmasses from the boundary layer to the upper troposphere without significant detrainment in the middle troposphere. Thus, only part of the upward transport that is contained in the 3-D resolved mean wind fields used in the advection algorithm actually represents large-scale upwelling processes, while the rest represents transport through deep cumulus clouds, the same transport that is also represented by the DCC parameterization.

A schematic showing the basic relationship between these mean advective and deep convective vertical mass fluxes in a typical contemporary CTM or GCM is presented in Fig. 1. The diagram represents any column in which the mean vertical velocity throughout most of the column is upward, and in which the deep convection parameterization is active, e.g., a tropical model column in the upward branches of the Hadley and Walker cells. The diagram is intentionally simplified to focus only on the issue being discussed here. It does not show the mid-level entrainment and detrainment associated with the DCC fluxes, nor the contribution in the lower troposphere by shallow convection, which has been posed by Folkins et al. (2008) as a "closed regional low-level circulation" in the tropics. These would modify the lower part of the diagram, but would not qualitatively modify the upper part or the overall connection of the mass fluxes to the largescale mean circulation. The actual variation with height of these mass fluxes in the context of the fields used in a CTM will be discussed in the next section.

The diagram includes mass fluxes $\left(F_{x}\right)$ and fractions of mass fluxes $\left(f_{x}\right)$ associated with various processes $(x)$. Within the framework of a typical CTM or GCM, the four fluxes are known quantities computed by the DCC and advection algorithms. On the other hand, the six fractions are implicit in the algorithms, and are defined for convenience here to help relate various components of the fluxes to the other fluxes and to real processes (e.g., the partial balancing of DCC updrafts by downdrafts and nearby mesoscale subsidence).

The mass fluxes are:

- $F_{\mathrm{LS}}(\mathrm{LS}=$ "large-scale"), the resolved mean upward mass flux (total upward minus total downward flux, by the combination of all contributing processes, averaged over the scale of a model grid cell); 


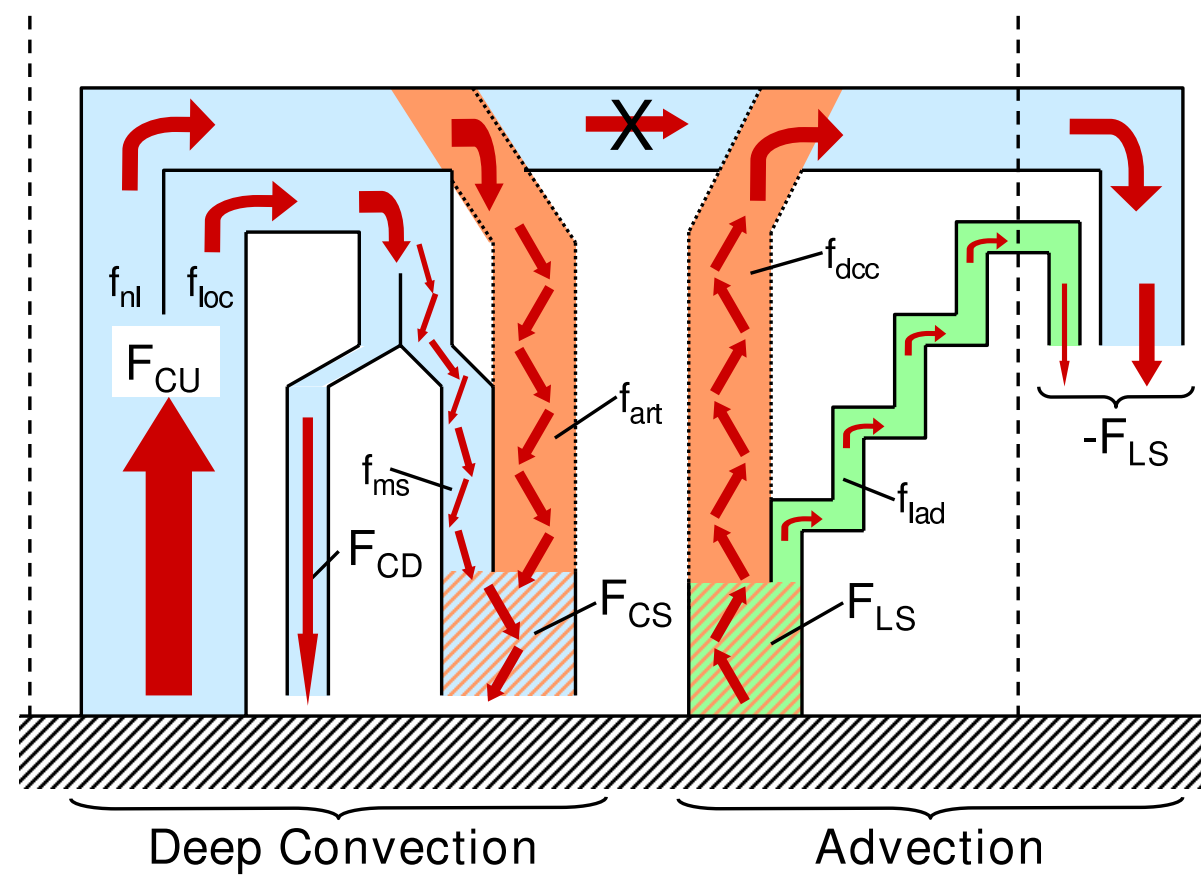

Fig. 1. Schematic of the mass fluxes and fractional components discussed in the text. The parameterized transport by deep convection is on the left, the components of simulated advective transport are on the right. The dashed vertical lines represent the bounds of a single model column (so that part of the depicted advective transport represents that outside the model column). The blue shaded regions represent the physical transport by deep cumulus convection, the orange shading represents the balance between the component of mean large-scale upwelling which is actually occurring through DCC updrafts and the mass-balance subsidence which is included in the DCC parameterization to guarantee individual mass conservation within the parameterization, and the green shading represents the "ladder" (non-convective) component of large-scale mean upwelling. The long, straight arrows (for $F_{\mathrm{CU}}$ and $F_{\mathrm{CD}}$ ) indicate the transport in the model occurs rapidly, directly connecting across multiple layers (e.g., between the BL and UT), while short, criss-cross arrows indicate the transport in the model occurs slowly, mixing one layer at a time, across the connected regions. See the text for further explanations, e.g., the large black "X" at the top of the figure.

- $F_{\mathrm{CU}}(\mathrm{CU}=$ "convective updraft"), the total upward mass flux through penetrative DCC updrafts (wherever it goes afterwards);

- $F_{\mathrm{CD}}(\mathrm{CD}=$ "convective downdraft"), the downward mass flux in rapid DCC downdrafts;

- $F_{\mathrm{CS}}$ (CS = "convective subsidence"), the downward mass flux due to slower mass-balance subsidence in the cloud-free part of the column.

The fractional components of the mass fluxes depicted in Fig. 1 are:

- $f_{\mathrm{nl}}\left(\mathrm{nl}=\right.$ "non-local"), the fraction of $F_{\mathrm{CU}}$ which in reality should be contributing to large-scale circulations, i.e., the component of lofted airmass which subsides far away from the updrafts;

- $f_{\text {loc }}$ (loc = "local"), the fraction of $F_{\mathrm{CU}}$ which is balanced by the sum of convective downdrafts and mesoscale subsidence in the immediate vicinity of the DCC (i.e., within the size range of a model grid cell);
- $f_{\mathrm{ms}}\left(\mathrm{ms}=\right.$ "mesoscale"), the fraction of $F_{\mathrm{CS}}$ which actually occurs as local mesoscale subsidence in the vicinity of the deep convective updrafts;

- $f_{\text {art }}($ art = "artificial"), the "artificial local subsidence", i.e., the component of $F_{\mathrm{CS}}$ which is included in the parameterization in the same column as the convective updrafts in order to balance $f_{\mathrm{nl}} \cdot F_{\mathrm{CU}}$, ensuring mass conservation;

- $f_{\mathrm{dcc}}(\mathrm{dcc}=$ "deep cumulus convection"), the fraction of $F_{\text {LS }}$ which represents the net resolved mean upwelling which is occurring through real deep cumulus convection (i.e., the mass flux in updrafts minus the balancing downward fluxes in downdrafts and mesoscale subsidence near the updrafts);

- $f_{\text {lad }}\left(\right.$ lad $=$ "ladder"), the fraction of $F_{\mathrm{LS}}$ which represents the contribution to the resolved mean upwelling which is not occurring through DCC, i.e., the component of the airmass which is transported from the surface to the upper troposphere by processes other than 
single deep convective updrafts which accomplish the transport in one step; this non-DCC transport is depicted here as a "ladder" of sequential upwelling through disconnected layers of shallow cumulus or stratus clouds.

It is important to note that though both $F_{\mathrm{CU}}$ and $F_{\mathrm{LS}}$ transport tracers from the BL to the UT, this transport is qualitatively different, with $F_{\mathrm{CU}}$ occurring as an eposidic, rapid, multi-layer transport, while $F_{\mathrm{LS}}$ is a slower, steady transport with complete mixing in each model layer on the way up. A similar difference applies to downdrafts versus massbalancing subsidence. This is depicted on the figure by the differences in the form of the arrows through each pathway.

There are several equations relating these fields and providing insight into the interpretation of their physical meaning and their representation in a CTM or GCM. First, we have made the assumption here that

$f_{\mathrm{dcc}}+f_{\mathrm{lad}}=1$

that is, that all of the airmasses being transported from the surface to the upper troposphere go through clouds of some form, rather than being transported entirely in clear air. Though some airmasses might reach the upper troposphere without going through either deep cumulus convective clouds or a sequence ("ladder") of lifting events in shallower clouds, we argue that this component of the total flux will be very small (and thus neglected in this discussion), given that airmasses cross many isentropes between the surface and the upper troposphere, and that an air parcel would have to start with a relative humidity of $\mathrm{RH}<1 \%$ in order to be able to be lifted over $10 \mathrm{~km}$ without condensation occurring (under the typical range of tropospheric conditions, e.g., Lawrence (2005)).

An important relationship between the mass fluxes themselves is that the upward DCC mass flux in any cell is balanced with the total downward mass flux in the DCC parameterization:

$F_{\mathrm{CU}}=F_{\mathrm{CD}}+F_{\mathrm{CS}}$

This is necessary to guarantee mass conservation, and is checked for explicitly in some convective transport algorithms, e.g., Lawrence and Rasch (2005).

One of the key features of the figure is the large black " $X$ " that crosses out the arrow at the top of the figure. As discussed above, in nature, some part of the airmass which is transported upward in DCC updrafts will then be horizontally advected away (e.g., poleward in the Hadley Cell). Since this connection is not explicitly present in models with a split operator treatment of DCC and advection, this connecting arrow is crossed out. Mathematically, this results in one of the most important relationships between the fluxes as defined here, which is that the fraction of DCC updraft mass flux that should leave the column and contribute to large-scale circulations $\left(f_{\mathrm{nl}}\right)$ exactly supplies the fraction of the mass-balance subsidence that occurs artificially due to the operator splitting $\left(f_{\text {art }}\right)$ :

$f_{\mathrm{nl}} \cdot F_{\mathrm{CU}}=f_{\text {art }} \cdot F_{\mathrm{CS}}$

Similarly, the amount of DCC updraft mass flux which should leave the column and contribute to large-scale circulations $\left(f_{\mathrm{nl}}\right)$ is also equal to the component of the resolved mean mass flux which represents convective lofting (rather than the "ladder" processes):

$f_{\mathrm{nl}} \cdot F_{\mathrm{CU}}=f_{\mathrm{dcc}} \cdot F_{\mathrm{LS}}$

Two further simple equations to note are the relationships between the pairs of fractions that sum to one: $f_{\mathrm{nl}}+f_{\text {loc }}=1$ and $f_{\mathrm{ms}}+f_{\mathrm{art}}=1$ (the third paired relationship, $f_{\mathrm{dcc}}+f_{\mathrm{lad}}=1$, was discussed above).

The figure makes it clear that there is a duplicate transport of air masses by the DCC parameterization and the advection algorithm: the flux $f_{\mathrm{dcc}} \cdot F_{\mathrm{LS}}$ is the component of the largescale upwelling which is actually occurring through DCC clouds, and is also present in the DCC parameterization as $f_{\mathrm{nl}} \cdot F_{\mathrm{CU}}$. One might think that this could lead to a doublecounting of the transport. This is avoided, however, by the additional, artificial fraction $f_{\text {art }}$ of the mass-balance subsidence flux, $F_{\mathrm{CS}}$, which is applied to each column in the convection parameterization. Since both the DCC and advection algorithms are individually mass-conserving, it is guaranteed that any vertical mass flux in the advection algorithm which should actually be occurring in the DCC parameterization will be exactly balanced by the residual subsidence term in the DCC parameterization. Thus from the perspective of tracer transport in "normal" model runs, if the advective and DCC transport algorithms were to be perfectly shape preserving, then the additional upward and downward transport would exactly cancel within each model time step, and we would not expect any significant net consequences for the simulations. Since, however, the transport algorithms are often not shape preserving, in contemporary models this can lead to numerical diffusion, which we discuss briefly in Sect. 4.

Returning to the issue of the studies discussed in the introduction, in which the parameterized convective transport of various tracers was switched off, we can now reconsider their interpretation in light of Fig. 1. These sensitivity simulations can be seen as turning off all the fluxes on the left hand side of the schematic (labeled "Deep Convection") for one or more tracers. The fluxes on the right hand side are still left over. Thus, only a part of the overall deep cumulus convective transport has actually been shut off in the simulations, namely $f_{\mathrm{loc}} \cdot F_{\mathrm{CU}}$, the component of the DCC updrafts and downdrafts which are associated with mesoscale subsidence in the vicinity of the cumulus towers. On the other hand, the component of DCC mass flux which is associated with large-scale circulations and subsidence far away, $f_{\mathrm{nl}} \cdot F_{\mathrm{CU}}\left(=f_{\mathrm{dcc}} \cdot F_{\mathrm{LS}}\right)$, will still have been present in all of the 
simulations, though not in the convection parameterization, rather in the form of a slow mean upwelling in the advection algorithm, which is no longer balanced by the additional subsidence term $f_{\text {art }} \cdot F_{\mathrm{CS}}$. Thus, we can expect these sensitivity simulations to likely underestimate the actual net effects of DCC transport in the models. A similar point was noted by Hess (2005), specifically in reference to the study of Mahowald et al. (1997b): "The method of Mahowald et al. ... gives less convective impact for long-lived tracers. This is most likely due to the importance of non-convective pathways to the upper troposphere when convection is turned off. It is not clear that these pathways necessarily exist in nature." The discussion above makes it clear that, even though these pathways do in principle exist (i.e., $f_{\text {lad }}$ in Fig. 1), at least some of the mass flux is indeed not occurring through these pathways in nature (rather really through DCC). In the next section we examine simulated mass fluxes to estimate the anticipated degree of significance of the non-convective versus convective transport to the upper troposphere.

A final note worth making before proceeding to the next section is that parameterizations of the thermodynamic impacts of deep convection in GCMs and NWP models are designed to bypass the need to explicitly simulate this connection between the airmass fluxes. This is done by instead computing the net diabatic effects of subgridscale convection on the resolved temperature and water vapor fields through an "apparent heat source" and "apparent moisture sink" (Yanai et al., 1973). While this treatment of deep convection is widely accepted for computing the influence of convective overturning on large-scale parameters such as the mean temperature and humidity profiles (e.g., Arakawa, 2004), it can have significant implications for tracers such as ozone, aerosols, and their precursors, as discussed below.

\section{Evidence of the significance: comparison of deep cu- mulus convective and large-scale mean mass fluxes}

\subsection{The issues}

The discussion in the previous section leaves three key questions to address in order to determine whether the misinterpretation of the sensitivity simulations noted above is significant, or only of academic interest:

1. how large is $f_{\mathrm{nl}}$ ? If it is small, then the leftover flux in the advection algorithm when convective transport is turned off is also relatively small;

2. how large is $f_{\mathrm{dcc}}$ ? If this were to be small, then the convective contribution to upwelling would also be small compared to the slower, diffusive "ladder" contribution;

3. although the mean upwelling that is left over in the advection algorithm $\left(f_{\mathrm{dcc}} \cdot F_{\mathrm{LS}}\right)$ is slow compared to the rapid convective updrafts, is it nevertheless rapid enough to expect significant impacts on key trace gases or aerosols in these kinds of sensitivity simulations?

In order to answer these questions, we need to determine the fractions $f_{x}$ based on the model output. Since these fractions are implicit, and not explicitly considered in the model algorithms, we need to make use of the relationships discussed above in light of Fig. 1 to try to solve for the six unknowns: $f_{\mathrm{nl}}, f_{\mathrm{loc}}, f_{\mathrm{ms}}, f_{\mathrm{art}}, f_{\mathrm{dcc}}$, and $f_{\text {lad }}$. So far we have discussed six independent equations relating the fluxes and fractions, namely Eqs. (1-4), and the two further relationships between the pairs of fractions that sum to one $\left(f_{\mathrm{nl}}+f_{\text {loc }}=1\right.$ and $\left.f_{\mathrm{ms}}+f_{\text {art }}=1\right)$. However, unfortunately, Eq. (2) is a simple identity between three known quantities, so that we really only have five equations left for six unknowns, and we cannot determine the fractions exactly based only on output from a CTM or GCM and/or from NWP analyses.

Nevertheless, we can attempt to establish reasonable bounds on the relative magnitudes of the various components of the mass fluxes. To do so, we can consider Riehl and Malkus (1958) and the many studies that have since followed (e.g., Folkins et al., 2008) which have asserted based on thermodynamic profile observations that slow, non-penetrative processes (e.g., advection and turbulent diffusion) cannot account for most of the vertical mixing, especially in the tropics. In turn, this means that at least half of the vertical mixing must be due to DCC, i.e., $f_{\mathrm{dcc}} \geq 0.5$, and based on Eq. (1), $f_{\text {lad }} \leq 0.5$. This has two implications for our discussion. First, for question 2 from above, we can thus assume that $f_{\text {dcc }}>f_{\text {lad }}$, i.e., $f_{\text {dcc }}$ is not small. Second, we can also use this to establish bounds on the relative magnitudes of the fluxes: using $f_{\text {lad }}=0.5$ will yield an approximate lower bound for the DCC component of the flux, while setting $f_{\text {lad }}=0.0$ (i.e., assuming that non-convective processes are non-existent or negligible) will provide an upper bound for the DCC component.

With these uppper and lower bounds as a basis, we can then directly address questions 1 and 3 . For question 1, if we take $f_{\text {lad }}=0.0$, then we can diagnose $f_{\text {nl }}$ by solving Eqs. (1) and (4) to yield

$$
f_{\mathrm{nl}}=\frac{F_{\mathrm{LS}}}{F_{\mathrm{CU}}}
$$

while if $f_{\text {lad }}=0.5$, then

$f_{\mathrm{nl}}=0.5 \frac{F_{\mathrm{LS}}}{F_{\mathrm{CU}}}$

Note that the first case becomes invalid to consider wherever $F_{\mathrm{LS}}>F_{\mathrm{CU}}$, since this would imply that $f_{\text {lad }}$ must be nonzero, or, if this occurs over a limited altitude range, that the large scale ascent may be occurring in clear air (which nevertheless implies $f_{\mathrm{dcc}}<1$ and thus, from Eq. (1), $f_{\mathrm{lad}}>0$ ). As seen below, this becomes particularly relevant in the tropical 
tropopause layer, where the Brewer-Dobson circulation begins to take over in determining the vertical transport. However, in the middle and lower troposphere this is a viable extreme case to consider for the sake of establishing upper and lower bounds on the relationships between the fluxes and fractional components.

For question 3, we can examine either $F_{\mathrm{LS}}$ or $0.5 F_{\mathrm{LS}}$ (for $f_{\text {lad }}=0.0$ or $f_{\text {lad }}=0.5$, respectively) to determine the timescale of vertical mixing that this would imply, and thus what kinds of tracers with comparable lifetimes would be expected to be strongly influenced by this residual transport term.

3.2 Significance of the large-scale vertical transport compared to DCC mass fluxes

To examine the issues discussed in the previous section, we use the mass fluxes from a frequently-used CTM, MATCH (Model of Atmospheric Transport and Chemistry, Rasch et al., 1997; Mahowald et al., 1997b,a; Lawrence et al., 1999). We focus particularly on the tropics, where zonal mean convective mass fluxes are largest, and a connection exists between deep convective updrafts and the Hadley and Walker cells, especially for convection in the inter-tropical convergence zone (ITCZ). We have chosen to compare the diagnosed advective and convective mass fluxes exactly as they are used in MATCH, since these fluxes are representative for one of the previous studies of the effects of DCC transport mentioned in the introduction (Lawrence et al., 2003b, with the exception of being at a higher resolution, T62 vs. T21, and without chemistry). Most of the other previous studies examining the effects of DCC transport have also been done with offline models like MATCH-MPIC, using their own re-diagnosed deep convective mass fluxes, so that the comparison we show in this section should be generally representative of what was being used in those studies. However, it is worth noting that for a more comprehensive, quantitative study focusing on a more fundamental understanding of the relationship between DCC mass fluxes and large scale circulation (e.g., the Hadley and Walker cells), it would be better to use the advective and convective mass fluxes directly from an NWP model like NCEP or ECMWF, or from a GCM. We return to this point briefly in the conclusions section.

MATCH is a "semi-offline" model which reads in basic meteorological driving data (surface pressure, geopotential height, temperature, horizontal winds, surface latent and sensible heating rates, and zonal and meridional wind stresses), and uses these to diagnose advection, vertical diffusion, and deep convection, as well as simulating online the tropospheric hydrological cycle (water vapor transport, cloud condensate formation and precipitation). The driving data for this simulation are from the NCEP/GFS analysis (Environmental Modeling Center, 2003) for the year 2005. The basic configuration used here is essentially the same as the MATCH-MPIC chemical weather forecasting and analysis system (Lawrence et al., 2003a), except that we do not compute the gas-phase photochemistry, and we employ a T62 resolution (about $1.9^{\circ} \times 1.9^{\circ}$ ), rather than the $\mathrm{T} 42$ resolution which is currently used for our operational chemical weather forecasting runs.

For deep convection, MATCH employs two parameterizations: Zhang and McFarlane (1995) for deep convection rooted in the boundary layer (BL), and Hack (1994) for shallow moist BL convection plus multi-layer convection originating above the BL. These are called sequentially, following the procedure in the NCAR/CCM3 (Kiehl et al., 1996). Since we are focusing on the effects of deep, penetrative convection, only the Zhang-McFarlane deep convective updraft mass fluxes are shown in the figures here; the mass fluxes from the Hack scheme are only significant below about $800 \mathrm{hPa}$, adding about $50 \%$ to the mass fluxes from the Zhang-McFarlane scheme, and a much smaller contribution in the upper troposphere, but they do not change our basic conclusions. The pressure velocity $(\Omega)$ fields used to compute the vertical large-scale mass fluxes shown in the figures discussed in this section are based on the NCEP horizontal wind fields; the divergence in these fields are used in MATCH to diagnose the vertical wind field, assuming zero fluxes at the upper and lower model boundaries, and applying small corrections to the horizontal wind fields to guarantee mass-wind consistency (Jöckel et al., 2001; see von Kuhlmann et al., 2003, for details of the computation here). The fluxes shown here thus correspond to those used for tracer transport by the advection routine in MATCH.

Figure 2 shows the zonal mean, monthly mean (January and July) profiles of the simulated convective updraft mass fluxes $\left(F_{\mathrm{CU}}\right)$ and the large-scale mass fluxes (where $F_{\mathrm{LS}}=\rho w=-\frac{\Omega}{g}$, where $\rho$ is the air density, $w$ is the vertical velocity, $g$ is the gravitation constant, and hydrostatic equilibrium is assumed). The deep convective mass fluxes are greatest in the tropics, extending into the tropical UT, as well as in the summer hemisphere mid-latitudes. The largescale mass fluxes in Fig. 2 depict the Hadley circulation as a region of strong mean upwelling (positive values) on the summer hemisphere side of the equator and strong downwelling in the winter hemisphere subtropics (approximately $10-35^{\circ} \mathrm{N}$ in January and $0-35^{\circ} \mathrm{S}$ in July). Here we already see a strong correspondence between the location and magnitude of the tropical deep convective updraft mass fluxes and the Hadley cell upwelling - that is, it is already apparent here that a substantial fraction of the DCC is feeding the Hadley cell (assuming, as discussed above, that $f_{\text {lad }} \leq 0.5$ ). It is worth noting here that the connection between the largescale mass fluxes and the deep convective mass fluxes is not explicit in MATCH, that is, the convection parameterization does not make direct use of the large-scale vertical wind or large-scale convergence. Nevertheless, there is a strong implicit connection via the water vapor and temperature profiles, which can be seen in these model fields. 

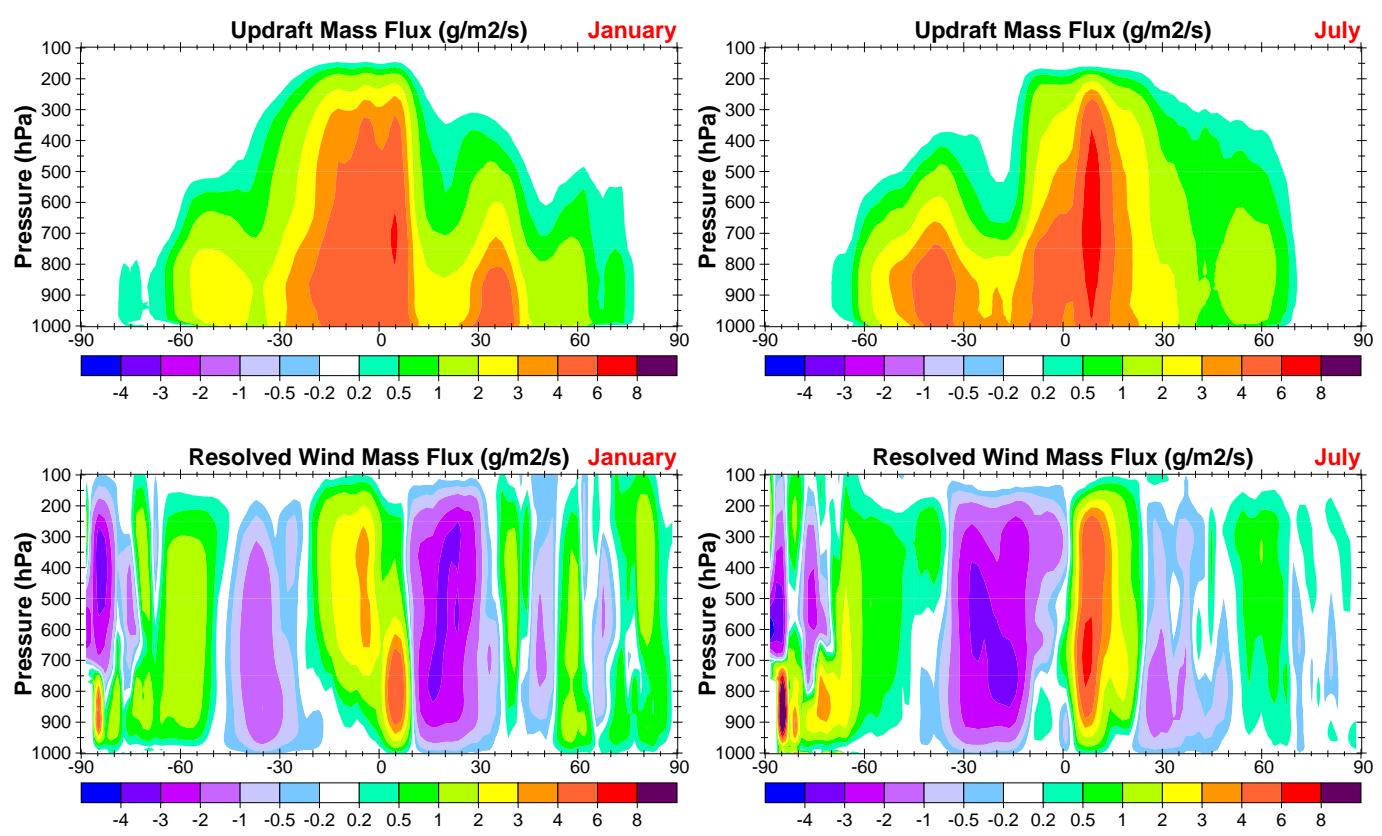

Fig. 2. Zonal means for January (left) and July (right), 2005, of the mass fluxes due to deep convective updrafts (top panels) and the mean resolved winds (bottom panels).

In addition to the Hadley cell, the Walker cells are also an important component of tropical circulation, with the upward branch mass fluxes occurring mostly through deep convective updrafts. In Fig. 3, we show the meridional mean convective updraft and large-scale mass fluxes, averaged over the regions of the upward branch of the Hadley cell. In the figures, the strongest Walker cell circulation, with upwelling over the western Pacific (about $120-180^{\circ} \mathrm{E}$ ) and subsidence over the eastern Pacific (about $180-90^{\circ} \mathrm{W}$ in January and $180-120^{\circ} \mathrm{W}$ in July) can be seen in both seasons, and other, weaker Walker cells can also be seen. Again, as for the zonal mean, the regions of stronger and weaker mean DCC mass fluxes correspond well to the upwelling and downwelling regions, respectively, although there is not a one-to-one correspondence, since the fluxes are not explicitly coupled, as noted above. Here again, the magnitudes of the DCC and large-scale mass fluxes are seen to be comparable, and in some cases in the upper troposphere the large-scale mass fluxes even exceed the DCC mass fluxes.

To directly compare the magnitudes of $F_{\mathrm{CU}}$ and $F_{\mathrm{LS}}$ for the model, we average over the regions depicted in the panels in Fig. 3 (i.e., the upward branches of the Hadley cells in each season). Figure 4 shows the mean vertical profiles for these regions for January and July. In this figure, the upward branch of the Hadley cell is represented by the large-scale vertical mass flux averaged over the region (red solid line), which must be balanced by subsidence outside the region, mostly in the downward branch of the Hadley cell. This flux becomes a substantial fraction of the parameterized convec- tive mass flux (blue dashed line) above about $800 \mathrm{hPa}$. Considering this in light of Eqs. (5) and (6), we can estimate a range of values for $f_{\mathrm{nl}}$ for any level based on the Hadley cell fluxes and the parameterized convective mass fluxes; the values for January and July at 800,500 , and $300 \mathrm{hPa}$ are listed in the second column of Table 1 . We see from these that, depending on the season and the assumed value of $f_{\text {lad }}$, between about $20 \%$ and $80 \%$ of the parameterized deep convective mass fluxes should be feeding into the Hadley cell. We have also examined output for individual timesteps. Although the relative magnitudes vary from day to day, our qualitative conclusions about the relationship between these fluxes still holds for all individual timesteps that we examined.

In addition to the Hadley cell fluxes, the Walker cell fluxes can be estimated by separately averaging over the cells with positive and negative large-scale vertical velocities (green dash-dot lines in Fig. 4). While it is possible for convective updrafts to be present in columns in which large-scale subsidence is occurring, this is generally not the case (as seen in Figs. 2 and 3). Furthermore, using this approach to averaging, the fluxes will also include smaller-scale vertical motions which are not parts of the Walker cells. When we examine output for individual timesteps (not shown), we find that this results in much larger values (generally by a factor of 2-3) for the green dash-dot lines. However, using monthly mean values causes these to largely be averaged out, leaving the Walker cells as the main residual zonal circulation patterns. 

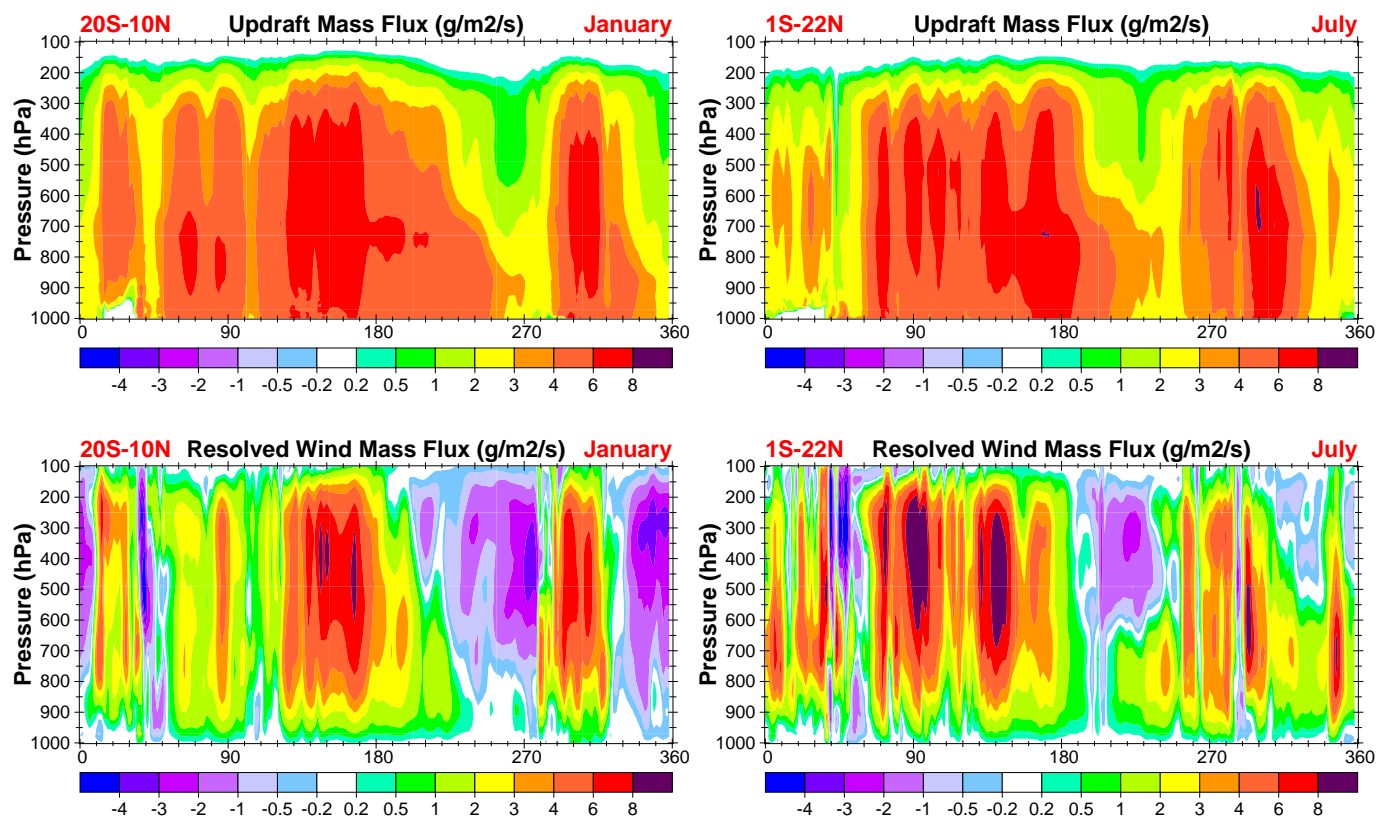

Fig. 3. Meridional means for January (left) and July (right), 2005, of the mass fluxes due to deep convective updrafts (top panels) and the mean resolved winds (bottom panels), averaged over the regions $20^{\circ} \mathrm{S}-10^{\circ} \mathrm{N}$ for January and $1^{\circ} \mathrm{S}-22^{\circ} \mathrm{N}$ for July.

The upward branches of the Walker cells are thus approximated by the difference between the positive green dash-dot line and the red line in Fig. 4. These fluxes are also nonnegligible relative to the regional mean parameterized DCC mass flux, especially in the middle and upper troposphere, as seen in the third column of Table 1. Interestingly, there is only a weak seasonality in the ratio of the Walker cell fluxes to the parameterized convective mass fluxes, with the values being nearly the same in January and July, while there is a stronger seasonality in the Hadley cell, with values about 1.5 times as large in July as in January (due to the greater influence of hemispheric asymmetry in land masses on the Hadley cell).

Finally, we can also apply Eqs. (5) and (6) to the sum of the Hadley and Walker cell fluxes (i.e., using the positive green dash-dot line for $F_{\mathrm{LS}}$ ), which yields the range of values listed in the final column of Table 1 . Note that a maximum value of $f_{\mathrm{nl}}=1$ is assumed (i.e., as discussed above, if $F_{\mathrm{LS}}>F_{\mathrm{CU}}$, then $f_{\text {dcc }}$ must be less than one). From these values of $f_{\mathrm{nl}}$, we conclude that on average in the tropics in MATCH, a significant fraction $(\geq 30 \%)$ of the mass-balance subsidence which occurs within the same column as the updrafts in the convection parameterization is an artifact which should really be occurring elsewhere. The implications of this are discussed in the following section.
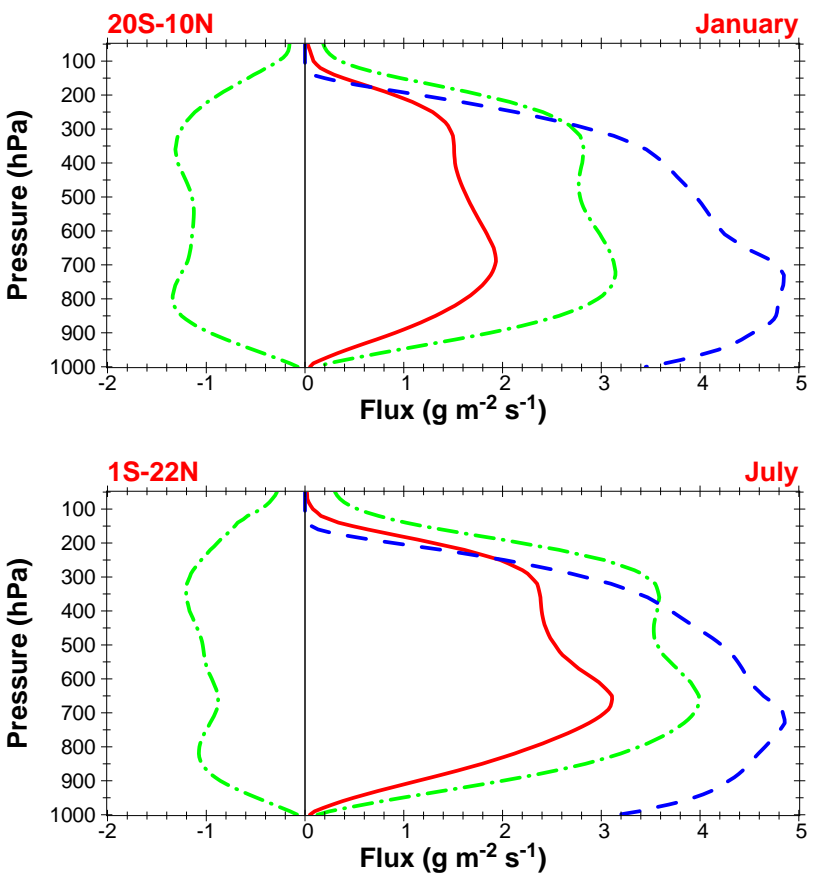

Fig. 4. Mean vertical profiles for January (top panel) and July (bottom panel), 2005, of the mass fluxes due to deep convective updrafts (blue dashed lines) and the mean resolved winds (net fluxes - red solid line; gross upward and downward fluxes - green dashdot lines), averaged over the regions $20^{\circ} \mathrm{S}-10^{\circ} \mathrm{N}$ for January and $1^{\circ} \mathrm{S}-22^{\circ} \mathrm{N}$ for July. 
Table 1. Ranges of values of $f_{\mathrm{nl}}$ for three pressure levels, calculated based on Eq. (5) and (6) and the profiles depicted in Fig. 4.

\begin{tabular}{lccc}
\hline Pressure (hPa) & Hadley cell & Walker cells & Combined \\
\hline $\begin{array}{l}\text { January } \\
300\end{array}$ & & & \\
500 & $0.25-0.51$ & $0.22-0.43$ & $0.47-0.94$ \\
800 & $0.21-0.41$ & $0.14-0.29$ & $0.35-0.70$ \\
& $0.17-0.34$ & $0.14-0.28$ & $0.31-0.62$ \\
July & & & \\
300 & $0.40-0.81$ & $0.21-0.41$ & $0.61-1.00$ \\
500 & $0.30-0.60$ & $0.12-0.25$ & $0.42-0.85$ \\
800 & $0.25-0.50$ & $0.11-0.23$ & $0.36-0.73$ \\
\hline
\end{tabular}

\section{Discussion}

Based on the results in the previous section and the summary in Table 1, it is evident that previous studies which have intended to examine the effects of deep convection on tracers by turning off the parameterized convective transport are likely to have underestimated the actual net effect of DCC in the models, perhaps significantly for some tracers. This is similar to what was noted by Hess (2005) in comparing the results of his tagged tracer method to the results of Mahowald et al. (1997b), as discussed above. This may also help to explain some of the notable discrepancy between the results of some of the other studies, especially given the differences in convective mass fluxes which were shown by Doherty et al. (2005), and thus the possibility of also having large relative differences between the residual transport fluxes left over in the advection scheme in each model.

Beyond showing that the fraction $f_{\mathrm{nl}}$ is significant (i.e., $\geq 30 \%$, in answer to question 1 from above), it is also important to consider how rapid the residual transport will be, to determine whether it can be expected to have a significant impact on various trace gases or aerosols (i.e., question 3 from above). The mass flux profiles averaged over the Hadley cell upwelling regions (Fig. 4) indicate a mean large-scale upward mass flux in the middle troposphere in the range of 3$4 \mathrm{gm}^{-2} \mathrm{~s}^{-1}$ (based on the green dash-dot lines). If we take a representative atmospheric density for this altitude range to be $0.7 \mathrm{~kg} \mathrm{~m}^{-3}$, this would imply a mean vertical velocity of the order of $0.5 \mathrm{~cm} / \mathrm{s}$, which would transport tracers from the boundary layer to the upper troposphere on average in about 20 days (for $f_{\text {lad }}=0$ ). If $f_{\text {lad }}$ were instead to be 0.5 , then this would correspond to a roughly 40-day transport timescale. On the other hand, in convectively active regions, the mean mass fluxes can be several times larger than the tropical mean, as seen in Figs. 2 and 3, resulting in mean transport times of less than 10 days for these regions. Furthermore, these are monthly mean values; during convectively active periods, the fluxes will be even larger, implying mean transport times of well below 10 days. This is rapid enough to expect it to impact most of the trace gases of interest, such as $\mathrm{O}_{3}$ (with a lifetime of days to weeks), $\mathrm{CO}$ (lifetime of a few weeks to a few months), various organic gases such as propane and butane (lifetimes of days to weeks), the reactive nitrogen $\left(\mathrm{NO}_{\mathrm{y}}\right)$ reservoir species like $\mathrm{HNO}_{3}$ and PAN (lifetimes of a week to months in the free troposphere), and to an extent even $\mathrm{NO}_{\mathrm{x}}\left(=\mathrm{NO}+\mathrm{NO}_{2}\right.$, with a lifetime of a day to several days). A moderate impact could also be expected if sensitivity simulations of this nature were to be conducted with aerosols, with lifetimes of a few days to a week.

What can be done to diagnose the impact of DCC transport on atmospheric tracers more accurately? Unfortunately, improving beyond the approach discussed above will probably be difficult to do in a consistent manner, since deep convection in regions of large-scale convergence such as the ITCZ represents an integral part of the underlying atmospheric circulation (e.g. the Hadley cell). One possibility would be to still apply the convective mass-balance subsidence to all tracers in the sensitivity simulations, while neglecting the transport in updrafts and downdrafts. Although it would be possible to do this and conserve tracer mass, the transport would not be monotonic (i.e., airmass, and thus tracer mass, would accumulate unrealistically in the lowest model layers). Furthermore, attempting to restore monotonicity by modifying the horizontal wind field in order to remove air mass convergence associated with deep convection clearly defeats the purpose of such an exercise. As described above, this situation has historically arisen because the split operator treatment of deep convection and advection led researchers to assume they could examine the net effects of DCC transport by turning off the parameterized mass fluxes for individual tracers. However, we contend that this problem would also apply to any future modeling system in which DCC and advection are coupled into one algorithm, since we do not see how it will be possible to neglect the convective transport component, yet still capture the atmospheric circulation patterns, without resulting in a non-monotonic transport problem.

Thus, it is not clear to us at present whether it will be possible at all to determine the net effects specifically of convective transport on atmospheric chemistry, given the design of current CTMs, though perhaps a methodology can eventually be developed in subsequent studies. One very effective methodology has recently been developed by Hess (2005) for artificial tracers, which are "tagged" upon going through convective updrafts. However, this only applies to these very simple, carefully-designed tracers, and it will be difficult or impossible to apply to complex real gases like ozone.

Finally, thus far we have focused our discussion on the implications for the interpretation of several previous studies. There are also two other important related issues which are worth briefly noting here.

First, the separate treatment of convective and advective mass fluxes can result in numerical diffusion, since, as noted above, the closed-column treatment of convective mass fluxes causes the upward motion of tracers in upwelling 
regions to be simulated by both the DCC parameterization and the advection scheme. A double counting is avoided, as discussed above. However, since transport schemes are normally not perfectly shape-preserving (Rood, 1987), this up-and-down motion (or the separate computation of the upward and downward vertical tendencies) will generally result in numerical diffusion. In particular, transport by convective mass fluxes is usually represented by a simple upwind differencing approach (e.g., Lawrence and Rasch, 2005), which tends to be highly numerically diffusive.

An example of the kinds of consequences this can lead to can be seen by considering tracer transport in the Hadley Cell. An airmass containing a pollutant tracer emitted at the surface is transported upward through the DCC parameterization in the ITCZ, and then advected poleward. If, while still in the upward branch of the Hadley Cell, it encounters another column in which deep convection is active, then the airmass will be forced downward somewhat due to the artificial mass-balancing subsidence present in the DCC parameterization. However, as seen in Fig. 1, the airmass will then also be transported back upward a compensating amount by the mean vertical winds used in the advection algorithm. Since in most models this transport is not perfectly shape preserving, numerical diffusion will result in the tracer signal being smeared out vertically, and the component which is articially transported downward in this way will be retained more effectively in the tropics than it should be.

While it is qualitatively clear that this should have an effect on tracer simulations, we are not aware of any previous published attempts to estimate whether it is likely to be significant or negligible in the context of a global transport model. We are also not aware of any attempts to quantify the actual turbulent diffusion which may be induced around convective clouds, which is normally not included explicitly in CTMs, and which may be either partly compensated or overcompensated by this numerical diffusion. A first attempt that we are aware of to explicitly couple DCC and advection in a CTM is being undertaken in the UCI model (building on the version described in Wild and Prather, 2000). So far, a first working version of the model has been developed in which the large-scale vertical velocity and convective subsidence are combined into a single vertical velocity for advection; a systematic comparison to older versions of the model where large-scale and convective vertical velocities are computed separately has not yet been done, but will probably provide substantial further insight into these issues, especially in terms of numerical diffusion, in the near future (J. Neu, personal communication, 2008).

The closed-column treatment of convection also has a few implications for Lagrangian trajectory models (e.g., LAGRANTO; Wernli and Davies, 1997) and Lagrangian parcel (or "particle") dispersion models (e.g., FLEXPART; Stohl et al., 1998) which are driven with 4-D wind fields from weather center analyses or from climate models. While some of these Lagrangian models include an explicit rep- resentation of deep convective transport (e.g., Forster et al., 2007), many do not. Interestingly, for those models without deep convection parameterizations, it has been noted that in some cases they are nevertheless able to represent atmospheric transport patterns well even in certain regions which are known to be characterized by extensive vertical transport within deep cumulus clouds, such as the Asian summer monsoon convection (Traub et al., 2003). This should not be interpreted as indicating that the upward transport in the trajectories is occurring due to large-scale upwelling in cloud-free regions, which is unrealistic on a widespread basis, as discussed above. Instead, this behavior in Lagrangian models is due to the use of 4-D resolved mean wind fields from GCMs or NWP models, which currently all include the mean component of the convective lofting which is associated with large-scale circulations. However, although the basic regional lofting will be present in such simulations, it can be expected that the mean rate of vertical transport by the resolved winds alone will underestimate the actual vertical transport flux which should be occurring through deep convection (compare the fluxes in Fig. 4), and thus that parcel age spectra in the upper troposphere will tend to overestimate the ages of parcels with origins at the Earth's surface. The slow, mean upwelling compared to episodic, rapid lifting in convective cells may further result in an underestimated variability in parcel age spectra, as well as errors in chemical processing and precipitation scavenging, if these are included. Further investigation in a separate study would be necessary to quantify the effects and to verify or refute these assertions.

\section{Conclusions and outlook}

In this study we have discussed previous studies of the effects of deep cumulus convection (DCC) on tracers and atmospheric chemistry. We have shown that in the chemistrytransport model MATCH, a significant fraction of the convective mass flux in the tropics is associated with the upward branches of the Hadley and Walker cells, which is in contradiction with the common assumption of balanced updraft, downdraft and subsidence air mass fluxes in each column in contemporary convection parameterizations. Thus, a substantial fraction of the local mass-balance subsidence in the deep convection parameterizations is actually an artifact, and should be occurring in model columns a few hundred to a few thousand km away. For sensitivity simulations in which the parameterized DCC transport is turned off for one or more tracers in order to assess its affects on atmospheric chemistry, this will result in an underestimate of the overall effects of convective transport, since a component of the convective transport, which is connected to the large scale mean circulations, will still be calculated by the advection scheme. Nevertheless, assessments such as those noted above are not without value, they just need to be reinterpreted 
as characterizing model behavior, differences between convection parameterizations, and the net effects of only a component of the parameterized (rather than the actual net) DCC tracer transport.

We have not been able to formulate a generally applicable way around this problem. Techniques such as that developed by Hess (2005) using carefully constructed artificial tracers are very informative about the effects of deep convection on such tracers. However, this only applies specifically to such tracers, and it is not clear how (or whether at all) such an analysis will be possible within the complex framework of the feedbacks involved in tropospheric chemistry. A further complication which applies to realistic atmospheric chemistry simulations is that soluble tracers (e.g., $\mathrm{HNO}_{3}$ and $\mathrm{H}_{2} \mathrm{O}_{2}$ ) can be strongly scavenged, and that there can be differences between the effective scavenging depending on whether the tracers are transported rapidly and episodically versus slowly and more continually between the BL and UT. A detailed analysis of this issue goes beyond the scope of this discussion, but it should be considered as an integral part of future analyses, especially multi-model intercomparisons of the effects of deep convection on atmospheric chemistry.

Although we have discussed this issue here as it pertains to large scale (global) models which employ DCC parameterizations, it is worth noting that a closely-related issue also applies to limited-area (e.g., cloud system resolving) models without DCC parameterizations. This was pointed out in Salzmann et al. (2004), in which we showed that applying periodic boundary conditions in a cloud system resolving model results in an unrealistically strong clear-air subsidence in regions of mean upwelling, and that for more realistic multi-day tracer simulations it is necessary to apply both lateral boundary conditions and large-scale vertical advection tendencies. Furthermore, evidence in support of the discussion in Sects. 2 and 3 is also available from such cloud system resolving models. Based on simulations (Salzmann et al., 2004) using data from the TOGA COARE campaign for the western Pacific Warm Pool, a region of strong net vertical ascent, we have found that downward transport takes place mainly in thin filaments associated with downdrafts in mesoscale convective systems, while mass-balancing subsidence occurs mostly outside the domain.

As noted above, further analysis of the fundamental relationship between parameterized deep cumulus convection and large-scale circulations, as well as of the present uncertainty due to differences in convection parameterizations, would best be done using the output from an NWP model or a GCM, rather than a CTM. An especially appropriate tool which we have begun to make use of for this purpose is the EMAC (ECHAM5/MESSy Atmospheric Chemistry) model (Jöckel et al., 2006), which is capable of employing several different deep convection parameterizations in stable, consistent simulations, all of which reproduce the main features of the observed global precipitation distribution, as discussed in Tost et al. (2006).
Finally, although we urge rethinking the interpretation of sensitivity simulations in which the parameterized DCC transport of one or more tracers is turned off, we would like to emphasize that we still strongly encourage performance of such simulations in the framework of model intercomparisons, such as planned within Activity 2 of the IGAC/SPARC Atmospheric Chemistry and Climate (AC\&C) initiative. If such analyses of the tracer and atmospheric chemistry responses are accompanied by information on the convective and large scale mass flux components such as discussed here, substantial insight into differences in model behavior and the simulated relationships between DCC, large scale circulations and atmospheric chemistry responses stands to be gained.

Acknowledgements. We would like to express our appreciation to Phil Rasch for his development and support of MATCH and for thoughtful comments, as well as to many other colleagues, including Jos Lelieveld, Holger Tost, Patrick Jöckel, Ian Folkins, Michael Prather, Leo Donner, Ruth Doherty, Jessica Neu, Ben Lintner, Jun-Ichi Yano, Volkmar Wirth and others for valuable discussions. We are grateful for the positive reviews and helpful comments from the editor, Owen Cooper, and the two anonymous referees. This work was partly supported by funding from the German Ministry of Education and Research (BMBF), project 07-ATC-02, and partly from the German Research Society (DFG) “TROPEIS” project (subproject B4).

Edited by: O. Cooper

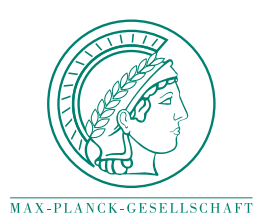

The publication of this article is financed by the Max Planck Society.

\section{References}

Arakawa, A.: The cumulus parameterization problem: past, present and future, J. Climate, 17, 2493-2525, 2004.

Collins, W. J., Stevenson, D. S., Johnson, C. E., and Derwent, R. G.: Role of convection in determining the budget of odd hydrogen in the upper troposphere, J. Geophys. Res., 104, 26927-26941, 1999.

Dickerson, R. R., Huffman, G. J., Luke, W. T., Nunnermacker, L. J., Pickering, K. E., Leslie, A. C. D., Lindsey, C. G., Slinn, W. G. N., Kelley, T. J., Daum, P. H., Delaney, A. C., Greenberg, J. P., Zimmerman, P. R., Boatman, J. F., Ray, J. D., and Stedman, D. H.: Thunderstorms: An important mechanism in the transport of air pollutants, Science, 235, 460-465, 1987.

Doherty, R. M., Stevenson, D. S., Collins, W. J., and Sanderson, M. G.: Influence of convective transport on tropospheric ozone and its precursors in a chemistry-climate model, Atmos. Chem. Phys., 5, 3205-3218, 2005,

http://www.atmos-chem-phys.net/5/3205/2005/.

Environmental Modeling Center: The GFS Atmospheric Model, NCEP Office Note 442, Global Climate and Weather Modelling 
Branch, National Centers for Environmental Prediction, Camp Springs, Maryland, 2003.

Erukhimova, T. and Bowman, K. P.: Role of convection in global-scale transport in the troposphere, J. Geophys. Res., 111, D03105, doi:10.1029/2005JD006 006, 2006.

Folkins, I., Fueglistaler, S., Lesins, G., and Mitovski, T.: A LowLevel Circulation in the Tropics, J. Atmos. Sci., 65, 1019-1034, 2008.

Forster, C., Stohl, A., and Seibert, P.: Parameterization of convective transport in a lagrangian particle dispersion model and its evaluation, J. Appl. Met. Clim., 46, 403-422, 2007.

Hack, J. J.: Parameterization of moist convection in the National Center for Atmospheric Research community climate model (CCM2), J. Geophys. Res., 99, 5551-5568, 1994.

Hess, P. G.: A comparison of two paradigms: The relative global roles of moist convective versus nonconvective transport, J. Geophys. Res., 110, D20302, doi:10.1029/2004JD005456, 2005.

Jöckel, P., v. Kuhlmann, R., Lawrence, M. G., Steil, B., Brenninkmeijer, C. A. M., Crutzen, P. J., Rasch, P. J., and Eaton, B.: On a fundamental problem in implementing flux-form advection schemes for tracer transport in 3-dimensional general circulation and chemistry transport models, Q. J. Roy. Meteor. Soc., 127, 1035-1052, 2001.

Jöckel, P., Tost, H., Pozzer, A., Brühl, C., Buchholz, J., Ganzeveld, L., Hoor, P., Kerkweg, A., Lawrence, M. G., Sander, R., Steil, B., Stiller, G., Tanarhte, M., Taraborrelli, D., van Aardenne, J., and Lelieveld, J.: The atmospheric chemistry general circulation model ECHAM5/MESSy1: Consistent simulation of ozone from the surface to the mesosphere, Atmos. Chem. Phys., 6, 50675104, 2006,

http://www.atmos-chem-phys.net/6/5067/2006/.

Kiehl, J. T., Bonan, G. B., Boville, B. A., Briegleb, B. P., Williamson, D. L., and Rasch, P. J.: Description of the NCAR Community Climate Model (CCM3), NCAR Tech. Note NCAR /TN-420+STAR, Nat. Cent. for Atmospheric Research, Boulder, CO, 1996.

Lawrence, M. G.: The relationship between relative humidity and the dew point temperature in moist air: A simple conversion and applications, B. Am. Meteorol. Soc., 86, 225-233, 2005.

Lawrence, M. G. and Rasch, P. J.: Tracer transport in deep convective updrafts: plume ensemble versus bulk formulations, J. Atmos. Sci., 62, 2880-2894, 2005.

Lawrence, M. G., Crutzen, P. J., and Rasch, P. J.: Analysis of the CEPEX ozone data using a 3D chemistry-meteorology model, Q. J. Roy. Meteor. Soc., 125, 2987-3009, 1999a.

Lawrence, M. G., Crutzen, P. J., Rasch, P. J., Eaton, B. E., and Mahowald, N. M.: A model for studies of tropospheric photochemistry: Description, global distributions, and evaluation, J. Geophys. Res., 104, 26 245-26 277, 1999b.

Lawrence, M. G., Rasch, P. J., von Kuhlmann, R., Williams, J., Fischer, H., de Reus, M., Lelieveld, J., Crutzen, P. J., Schultz, M., Stier, P., Huntrieser, H., Heland, J., Stohl, A., Forster, C., Elbern, H., Jakobs, H., and Dickerson, R. R.: Global chemical weather forecasts for field campaign planning: predictions and observations of large-scale features during MINOS, CONTRACE, and INDOEX, Atmos. Chem. Phys., 3, 267-289, 2003a, http://www.atmos-chem-phys.net/3/267/2003/.

Lawrence, M. G., von Kuhlmann, R., Salzmann, M., and Rasch, P. J.: The balance of effects of deep convective mix- ing on tropospheric ozone, Geophys. Res. Lett., 30, 1940, doi:10.1029/2003GL017644, 2003b.

Lelieveld, J. and Crutzen, P. J.: Role of deep cloud convection in the ozone budget of the troposphere, Science, 264, 1759-1761, 1994.

Lintner, B. R.: Mechanisms of passive tracer interhemispheric transport: an analysis of model-derived and observational interhemispheric transport climatology and interannual variations, Ph.D. Dissertation, University of California, Berkeley, 264 pp., 2003.

Mahowald, N. M., Prinn, R., and Rasch, P. J.: Deducing $\mathrm{CCl}_{3} \mathrm{~F}$ emissions using an inverse method and chemical transport models with assimilated winds, J. Geophys. Res., 102, 28153 $28168,1997 \mathrm{a}$.

Mahowald, N. M., Rasch, P. J., Eaton, B. E., Whittlestone, S., and Prinn, R. G.: Transport of ${ }^{222}$ radon to the remote troposphere using the Model of Atmospheric Transport and Chemistry and assimilated winds from ECMWF and the National Center for Environmental Prediction/NCAR, J. Geophys. Res., 102, 28 13928 152, 1997b.

Pickering, K. E., Thompson, A. M., Dickerson, R. R., Luke, W. T., McNamara, D. P., Greenberg, J. P., and Zimmerman, P. R.: Model Calculations of tropospheric ozone production potential following observed convective events, J. Geophys. Res., 95, 14 049-14 062, 1990.

Pickering, K. E., Thompson, A. M., Scala, J. R., Tao, W., Dickerson, R. R., and Simpson, J.: Free tropospheric ozone production following entrainment of urban plumes into deep convection, J. Geophys. Res., 97, 17 985-18 000, 1992.

Pickering, K. E., Thompson, A. M., Tao, W., and Kucsera, T. L.: Upper tropospheric ozone production following mesoscale convection during STEP/EMEX, J. Geophys. Res., 98, 8737-8749, 1993.

Rasch, P. J., Mahowald, N. M., and Eaton, B. E.: Representations of transport, convection, and the hydrologic cycle in chemical transport models: Implications for the modeling of short lived and soluble species, J. Geophys. Res., 102, 28 127-28 138, 1997.

Riehl, H. and Malkus, J. S.: On the heat balance in the equitorial trough zone, Geophysica, 6, 503-538, 1958.

Rood, R. B.: Numerical Advection Algorithms and Their Role in Atmospheric Transport and Chemistry Models, Rev. Geophys., 25, 71-100, 1987.

Salzmann, M., Lawrence, M. G., Phillips, V. T. J., and Donner L. J.: Modelling tracer transport by a cumulus ensemble: lateral boundary conditions and large scale ascent, Atmos. Chem. Phys., 4, 1797-1811, 2004, http://www.atmos-chem-phys.net/4/1797/2004/.

Stohl, A., Hittenberger, M., and Wotawa, G.: Validation of the Lagrangian particle dispersion model FLEXPART against large scale tracer experiment data, Atmos. Environ., 32, 4245-4264, 1998.

Tost, H., Jöckel, P., and Lelieveld, J.: Influence of different convection parameterisations in a GCM, Atmos. Chem. Phys., 6, 54755493, 2006, http://www.atmos-chem-phys.net/6/5475/2006/.

Traub, M., Fischer, H., de Reus, M., Kormann, R., Heland, J., Ziereis, H., Schlager, H., Holzinger, R., Williams, J., Warneke, C., de Gouw, J., and Lelieveld, J.: Chemical characteristics assigned to trajectory clusters during the MINOS campaign, At- 
mos. Chem. Phys., 3, 459-468, 2003,

http://www.atmos-chem-phys.net/3/459/2003/.

von Kuhlmann, R., Lawrence, M. G., Crutzen, P. J., and Rasch, P. J.: A model for studies of tropospheric ozone and non-methane hydrocarbons: Model description and ozone results, J. Geophys. Res., 108, 4294, doi:10.1029/2002JD002 893, 2003.

Wernli, H. and Davies, H. C.: A Lagrangian-based analysis of extratropical cyclones. I: The method and some applications, Q. J. Roy. Meteor. Soc., 123, 467-489, 1997.

Wild, O. and Prather, M. J.: Excitation of the primary tropospheric chemical mode in a global three-dimensional model, J. Geophys. Res., 105, 24 647-24 660, 2000.
Yanai, M., Esbensen, S., and Chu, J.: Determination of bulk properties of tropical cloud clusters from large-scale heat and moisture budgets, J. Atmos. Sci., 30, 611-627, 1973.

Zhang, G. J. and McFarlane, N. A.: Sensitivity of Climate Simulations to the Parameterization of Cumulus Convection in the Canadian Climate Centre General Circulation Model, Atmos. Ocean, 33, 407-446, 1995. 